\title{
Erratum to: Omental infarct: CT imaging features
}

\author{
A. K. Singh, D. A. Gervais, P. Lee, S. Westra, P. F. Hahn, R. A. Novelline, P. R. Mueller \\ Division of Abdominal Imaging and Interventional Emergency Radiology, Massachusetts General Hospital, 55 Fruit Street, \\ Boston, Massachusetts 02114, USA
}

\section{Erratum to: Abdom Imaging (2006) 31:549-554 DOI 10.1007/s00261-005-0251-6}

This article was inadvertently published a second time under DOI: 10.1007/s00261-006-9024-0.

Official publication is under DOI: 10.1007/s00261-005-0251-6 appearing in Abdom Imaging (2006) 31:549-554.

The online version of the original article can be found under doi:10.1007/s00261-005-0251-6. 